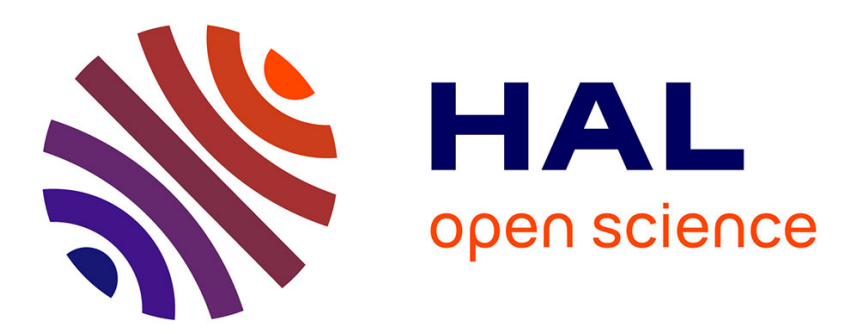

\title{
Impact of maternal obesity on the metabolic profiles of pregnant women and their offspring at birth
}

Romain Desert, Cécile Canlet, Nathalie Costet, Sylvaine Cordier, Nathalie

Bonvallot

\section{- To cite this version:}

Romain Desert, Cécile Canlet, Nathalie Costet, Sylvaine Cordier, Nathalie Bonvallot. Impact of maternal obesity on the metabolic profiles of pregnant women and their offspring at birth. Metabolomics, 2015, 11 (6), pp.1896-1907. 10.1007/s11306-015-0836-1 . hal-01195742

HAL Id: hal-01195742

https://hal-univ-rennes1.archives-ouvertes.fr/hal-01195742

Submitted on 19 Oct 2015

HAL is a multi-disciplinary open access archive for the deposit and dissemination of scientific research documents, whether they are published or not. The documents may come from teaching and research institutions in France or abroad, or from public or private research centers.
L'archive ouverte pluridisciplinaire HAL, est destinée au dépôt et à la diffusion de documents scientifiques de niveau recherche, publiés ou non, émanant des établissements d'enseignement et de recherche français ou étrangers, des laboratoires publics ou privés. 
Impact of maternal obesity on the metabolic profiles of pregnant women and their offspring at birth

DESERT ROMAIN $(1,2,3)$, CANLET CECILE (4), COSTET NATHALIE $(1,3)$, CORDIER SYLVAINE $(1,3)$, BONVALLOT NATHALIE $(1,2,3,4)$

(1) INSERM UMR1085 IRSET, Rennes, France

(2) EHESP Rennes, Sorbonne Paris Cité, France

(3) University of Rennes I, Rennes, France

(4) INRA UMR 1331 Toxalim; University of Toulouse, INP, ENVT, EIP, UPS, UMR1331, Toulouse, France

\section{Corresponding author}

Nathalie Bonvallot

EHESP School of Public Health, INSERM UMR1085 (IRSET), Avenue du Professeur Léon Bernard, CS74312, F-35043 Rennes Cedex, France. Tel: +332 990226 22. Fax: +3329902 26 75. E-mail: nathalie.bonvallot@ehesp.fr

\section{Other authors}

Romain Désert, EHESP, INSERM UMR 991, Université Rennes 1 - Hôpital Pontchaillou, 2 rue Henri Le Guilloux, 35033 Rennes, France. Tel : +332 232338 52. Fax : +332 99540137. Email: romain.desert@inserm.fr

Nathalie Costet, INSERM UMR 1085 (IRSET), Université Rennes 1, Avenue du Professeur Léon Bernard, CS74312, F-35043 Rennes Cedex, France. Tel : +332 232361 88. E-mail: nathalie.costet@univ-rennes1.fr 
Cécile Canlet, INRA - UMR 1331 TOXALIM, Bâtiment A, 180 Chemin de Tournefeuille, BP 93173, 31027 Toulouse cedex 3, France. Tel: +335 612857 13. Fax: +335 612852 44. Email: cecile.canlet@ toulouse.inra.fr

Sylvaine Cordier, INSERM UMR 1085 (IRSET), Université Rennes 1, Avenue du Professeur Léon Bernard, CS74312, F-35043 Rennes Cedex, France. Tel: +332 232359 29. E-mail: sylvaine.cordier@univ-rennes1.fr

\section{Short running title:}

Obesity and metabolomics in pregnant women

\section{Competing financial interests declaration}

The authors declare they have no competing financial interests.

\section{Compliance with Ethical Requirements}

The authors declare they comply with Ethical requirements. 
Abstract: Obesity is currently an increasing public health problem. The intra-uterine environment plays a critical role in foetal development. The objective of this study is to investigate the association of obesity with modifications in the metabolic profiles of pregnant women, and their new-borns. Based on the PELAGIE cohort (Brittany, France), a sample of 321 pregnant women was divided into 3 groups according to their body mass index (BMI) (normal, over-weight and obese). Nuclear magnetic resonance-based metabolomics analyses were performed on maternal urine and cord-blood samples. Partial Least Squares Regression-Discriminant Analysis (PLS-DA), polytomous and logistic regressions were used to differentiate the metabolic profiles of the $3 \mathrm{BMI}$ groups after adjusting for potential confounders.

Specific profiles were observed for the overweight and obese women (BMI>25) compared to the normal-weight women: they had a decrease in urinary hippurate excretion associated with a decrease in phenylalanine and an increase in creatinine. We also showed an increase in the urinary excretion of lactate, citrate, acetate, creatine, and lysine only in obese women $(\mathrm{BMI}>30)$ compared to the normal-weight women. The PLS-DA modelling did not reveal any significant difference between the cord-blood metabolic profiles of newborns according to maternal BMI - although infants born of obese women had a higher birth weight and a lower Apgar score. Our results confirmed the potential link between obesity and gut microbiota disruption (changes in urinary acids), as well as energy and amino-acid metabolism but did not reveal any disruption among newborns.

Keywords: Metabolomics, Obesity, Biomarkers, System biology. 


\section{Introduction}

Obesity, associated with type II diabetes or cardiovascular diseases, has reached epidemic status. A third of American women of reproductive age are obese (Orsi et al., 2011). Now, epidemiological studies have shown increased birth weight in new-borns from obese mothers, associated with a higher risk of developing obesity in the future (Muhlhausler et al., 2013; Symonds et al., 2013). Epidemiological studies, experimentations on animals and placental models have shown the critical role played by the intrauterine environment in foetal development, including a direct transmission of obesity or metabolic pathologies (Dong et al., 2013; Symonds et al., 2013). For example, the male offspring of mice with gestational obesity developed excess weight, insulin resistance and hyperleptinemia at adulthood, without any post-natal obesogenic influence (Dahlhoff et al., 2014). Furthermore, several human studies based on mother-child cohorts have found an association between maternal obesity and disrupted childhood metabolism associated with cardiovascular diseases (Godfrey and Barker, 2000; O’Reilly and Reynolds, 2013; Wen et al., 2011).

These phenomena, known as "foetal programming" involve different mechanisms (Bouanane et al., 2010; Symonds et al., 2013; Zambrano and Nathanielsz, 2013). First of all, several studies provide supporting evidence on the involvement of an epigenetic mechanism. In one human cohort, modifications in DNA methylation at the leptin and adiponectin genes have been observed in placentas exposed to maternal gestational diabetes mellitus (Bouchard et al., 2012, 2010). In another, global methylation levels in the placenta and umbilical cord-blood was higher with obesity (Nomura et al. 2014).

Secondly, overexpression of certain miRNA in foetal muscle from obese mothers has been shown in a model of maternal obesity in ewes, suggesting a decrease in adipogenic markers and in inflammatory cytokines (Yan et al., 2013). In rats, the wiring of connections within the Hypothalamic Arcuate Nuclei (HAC) - a complex energy and appetite control system - occurs 
in the first 3 weeks of life coincident with a peak in leptin in the new-born pups' peripheral blood. Pups born of obese mothers have a distorted plasma leptin peak that is longer lasting and higher in amplitude (Kirk et al., 2009). This could be the sign of a perturbation in HAC development, resulting in future resistance to leptin feedback and energy balance alterations. Hormonal changes in foetuses from obese mothers - such as increased cortisol levels or decreased thyroxine (T4) levels - have also been reported as potential mechanisms involved in programmed obesity (Guzmán et al., 2006; Magyar et al., 1980; Nuermaimaiti Tuersunjiang, 2013; Suter et al., 2012). Changes in placenta function have also been observed, with inflammation and changes in glucose or amino acid transport rates (Challier et al., 2008; Farley et al., 2010; Jones et al., 2009). Maternal reactive oxygen and nitrogen species, which are associated with intrauterine oxidative stress, also seem to play a role in obesity programming. Indeed, oxidative stress is suspected of being implicated in mitochondrial damage, changes in pancreas functions and dysfunctions of the electron transport chain in skeletal muscle (Shelley et al., 2009; Simmons et al., 2005). There is also supporting evidence for a link between maternal exposure to xenobiotics and chemicals, and higher Body Mass Index (BMI) in offspring (Janesick and Blumberg, 2011; Karmaus et al., 2009; Smink et al., 2008).

Otherwise, some of these mechanisms (epigenetics, corticosteroids, miRNA or maternal exposure to chemicals) are investigated for the understanding of the programming of obesity for children exposed to famine in utero (Inadera, 2013). Most studies have been undertaken in animal models.

Metabolomics describes the study of the metabolome, which is defined as the collective set of metabolites produced or present in a sample of interest, for example blood or other biological fluid, tissue lysate or cells. Metabolomics based on spectroscopic techniques, is able to generate "fingerprints" or metabolic profiles that can be correlated with phenotypes. The metabolic profile constitutes the ultimate step in the cellular response, and is considered the key link 
between genes and phenotypes (Fiehn, 2002). It has come to be widely used in recent years to identify metabolic pathways modified by disease (Vinayavekhin et al., 2010). This technique has already proved its capacity to study the physiopathology of obesity in animal and human studies (Zhang, Sun, et Wang 2013). When it is non-targeted, variations can be shown in the levels of metabolites between different groups of population without a priori.

Metabolomics have already been used to investigate metabolic differences between pregnant and non-gravid women (Lowe and Karban, 2014) as well as to analyse metabolic differences between obese and normal weight people (Xie et al., 2012a). The aim of the present study is to investigate the existence of differential urinary metabolic profiles in pregnant women according to their obesity status, and to understand whether observed changes are associated with modifications in the new-born metabolic profile. Thus, we have used Nuclear Magnetic Resonance (NMR)-based metabolomics analysis on urinary and cord-blood samples of pregnant women and new-borns from the PELAGIE cohort (Brittany, France). To our knowledge, this is the first study to investigate the maternal programming of obesity in a human population, using metabolomics.

\section{Material and Methods}

\section{Population, sample collection and obesity groups}

The population was selected from the PELAGIE cohort, which includes 3,421 pregnant women in Brittany (France) enrolled during early pregnancy from the general population by gynaecologists, between 2002 and 2006. Gynaecologists informed the women of the nature of the study and asked them to participate, after providing written consent. This consent was accompanied by a letter of information describing the goal of the study, the consortium, data collection procedures and follow-up after birth (via questionnaires and medical examinations). Explicit mention was made of the right to refuse to participate, and the fact that such a refusal 
would not have any effect on the woman's relationship with her doctor. Both the INSERM (French National Institute of Health and Medical Research) ethics committee and the National Commission in charge of Data Protection (CNIL) approved the study procedures (Nu902076; 31 may 2002). A detailed description of this cohort is available elsewhere (Chevrier et al., 2011). At inclusion, during the first trimester of the pregnancy (4th to 15 th week), women had to complete a self-report questionnaire including information about social and demographic characteristics, diet and lifestyle, and data on their height and weight (used to calculate BMI). They also had to return a first morning void urine sample that they collected and transferred into two vials containing nitric acid to avoid bacterial degradation. No blood collection was planned at this step of inclusion because of the absence of hospital appointment. Samples were mailed to the study laboratory in a pre-stamped package at ambient temperature, with routine delivery taking 1 to 3 days. Upon receipt, the $10 \mathrm{~mL}$ samples were frozen and stored at $-20^{\circ} \mathrm{C}$. At birth, medical data on health outcomes were obtained and cord-blood samples were collected. After centrifugation, serum samples were analysed by hospital laboratories and stored at $-20^{\circ} \mathrm{C}$.

Pregnant women were selected from the PELAGIE according to the following criteria: living infant at birth $(\mathrm{n}=3322)$ and availability of both urinary and cord blood samples for each mother-child pair $(n=1061)$. In addition, one year of inclusion (2004) was selected, to avoid potential variability due to different storage durations of biological samples. A detailed description of this methodology is published elsewhere (Bonvallot et al., 2013). Of the 338 eligible women, those whose BMI was unavailable or below 18.5 were excluded $(n=15)$, because low body weight can influence metabolic profiles (Norman et al., 2014; SarlioLähteenkorva et al., 2004). Finally, the population analysed included 323 women, who were classified into 3 groups of BMI, according to the World Health Organization (WHO)'s definition (WHO Expert Consultation, 2004): the first group comprised women with a BMI of 
between 18.5 and $<25$ (normal weight), the second those with a BMI between 25 and $<30$ (overweight) and the third, those with a BMI of 30 or more (obese).

\section{Metabolomics analyses}

Urinary sample preparation: After thawing at room temperature and vortexing, $500 \mu \mathrm{L}$ of urine were mixed with $200 \mu \mathrm{L}$ of phosphate buffer ( $\mathrm{pH}$ 7.39) prepared in $\mathrm{D}_{2} \mathrm{O}$ to which was added sodium 3-trimethylsilyl-1-[2,2,3,3,- $\left.{ }^{2} \mathrm{H}_{4}\right]$-propionate (TSP, $1 \mathrm{mM}$ ). The phosphate buffer is used to minimize variations in chemical shift values in the acquired NMR spectra due to $\mathrm{pH}$ differences. TSP served as a chemical shift reference and $\mathrm{D}_{2} \mathrm{O}$ served as a field-frequency lock for the NMR spectrometer. Each sample was vortexed and centrifuged for 10 min at 8,000 rpm to remove any precipitate. Then, $600 \mu \mathrm{L}$ aliquots were transferred to standard $5 \mathrm{~mm}-\mathrm{NMR}$ tubes (Norell ST 500, Landisville, NJ) for analysis.

Serum sample preparation: After thawing at room temperature and vortexing, $200 \mu \mathrm{L}$ of serum were mixed with $500 \mu \mathrm{L}$ of $\mathrm{D}_{2} \mathrm{O}$ which served as a field-frequency lock for the NMR spectrometer. Each sample was vortexed and centrifuged for $10 \mathrm{~min}$ at $8,000 \mathrm{rpm}$ to remove any precipitate. Then, $600 \mu \mathrm{L}$ aliquots were transferred to NMR tubes for analysis.

Metabolomics analyses: Metabolomics analyses of urine and cord-blood samples were made by NMR spectroscopy using a Bruker Avance DRX-600 operating at $600.13 \mathrm{MHz}$ (Bruker Biospin, Germany) and equipped with an autosampler and an inverse ${ }^{1} \mathrm{H}_{-}-{ }^{13} \mathrm{C}-{ }^{15} \mathrm{~N}$ cryoprobe. All NMR spectra were phase- and baseline-corrected manually using Topspin (V2.1, Bruker Biospin, Germany). The spectral region containing residual water resonance $(\delta$ 5.515-6.600) was removed and spectra were digitized to 642 and 751 buckets corresponding to $0.01 \mathrm{ppm}$ intervals using the AMIX software package (V3.9.11, Bruker Biospin, Germany). Each integrated region was divided by the total spectral intensity in order to normalise values. Spectra 
acquisition, pre-processing step, and metabolite identification have been described previously (Bonvallot et al., 2013).

Statistical analysis: metabolic profiles according to BMI groups. To investigate the association of obesity with specific metabolomic profiles, we used Partial Least Square Discriminant Analyses (PLS-DA) and multivariate logistic regression models. Our objective was not to strictly build predictive models for obesity but rather to study variations in both mother and newborn metabolic profiles according to maternal obesity.

The PLS-DA approach was chosen because it handles highly collinear and noisy data, such as spectral data and it has already been used in epidemiological studies which investigated subtle health effects in relation to highly variable spectral data (Waterman et al., 2009). It allows identifying among the spectrum the most important variables which discriminate the groups of interest, using statistics such as the variable importance on projection (VIP).

Maternal urine and cord blood spectral data were analysed separately. The original digitized NMR spectral data were imported into the R software (version 3.1.1) for multivariate statistical analysis. A preliminary principal component analysis (PCA) was implemented to remove potential outliers. Data were then Pareto-scaled to reduce relative importance of large values, while partially preserving data structure (Worley and Powers, 2013). PLS-DA were applied to Pareto-scaled data. In PLS-DA, linear combinations of NMR buckets are constructed to maximize covariance between the $\mathrm{Y}$ (BMI groups) and (NMR buckets) $\mathrm{X}$ matrices. Observations are then projected onto planes defined by a few of these linear combinations (also interpreted as latent variables). Various PLS-DA models were generated: a 3-level model measuring the link between the metabolic profiles and the mothers' BMI in 3 groups (Normal vs. Overweight vs. Obese) and four 2-level models measuring the link with BMI in 2 groups (Normal vs. others, Obese vs. others, Normal vs. Overweight, Overweight vs. Obese). The quality of the 3-level models was assessed by the Q2 and the R2 parameters defined as followed: 
- $Q 2=1-\frac{P R E S S_{n}}{R S S_{n-1}}$, where PRESS is the predicted residual sum of squares; RSS, the residual sum of squares and $n$, the number of latent variables (LV)

- $R 2=1-\frac{P R E S S}{T S S}$, where TSS is the total sum of squares

The quality of the 2-level models was assessed by the Q2, R2 and the area under the ROC curve (AUROC) criteria, following a 3-2 double-k-fold cross-validation. This consists of two nested cross-validation loops. The modelling procedure, including the cross-validation that determines the best number of Latent Variables (LV), using the lower PRESS criteria, forms the inner loop. Cross-validation for error estimation takes place in the outer loop. Double cross-validation is recommended in PLS-DA analysis (Smit et al., 2007; Szymańska et al., 2012). Here, a limited number of folds for cross validation ( $n=3$ in outer loop and $n=2$ in inner loop) were chosen to keep an adequate number of obese mothers in each fold $(n=6$ or 7$)$. A random draw was performed to allow equal distribution of Obese and Overweight in each fold. A permutation test (1,000 iterations) was conducted for each PLS-DA model to test for validity. Finally, the spectral regions (buckets) having VIP above 2 were considered as being significantly associated with the maternal BMI status and were used to identify the metabolites of interest. Kruskal Wallis tests using crude spectral data were used to confirm the relationships between BMI groups and concentrations of metabolites in urine or in serum previously identified.

\section{Adjustment for confounding factors}

As PLS-DA did not allow for adjustment, polytomous and logistic regressions were then used to assess the association of urinary metabolic profiles with the BMI group (3 levels) after adjustment for women's individual characteristics. For each metabolite previously identified from the PLS-DA, the corresponding buckets with VIP > 2 were simultaneously introduced in the models. Results from these analyses were reported as a global trend (direction of the 
association) and an adjusted $\mathrm{p}$ value. The literature suggested some major confounding factors. Age, educational level, alcohol and tobacco consumption, food habits (fruit and fish consumption), proportion of area covered by cereal crops in the municipality of residence during pregnancy (reflecting pesticide exposure) and Apgar score (at $5 \mathrm{~min}$, only in the analysis of cord-blood) were considered as potential confounders and were retained in the model if the likelihood ratio (LR) test was statistically significant for at least one metabolite. Then, a backward selection using the LR test was performed to select confounders with an impact in term of goodness of fit. Finally, none of the confounders has been kept in the models.

\section{Results}

Preliminary PCA identified 2 outliers among the women (urinary analyses). The first one had a high concentration of urinary glucose and was identified as diabetic. The second had no specific characteristics compared to the other individuals but a high concentration of hippurate was detected in her urinary sample. The preliminary PCA among the new-borns (serum analyses) did not identify any outlier. Table I describes the characteristics of the 321 women finally included in the analyses. Mean maternal age was 30.3 and most of these women had a high educational level (university degree). Tobacco and alcohol consumption was limited $(28.2 \%$ and $15.9 \%)$

Most of the women were of normal-weight $(n=256), 46$ were overweight and only 19 were considered obese according to the WHO definition. Overweight and obese women had higher parity than normal weight women $(\mathrm{p}=0.03)$, higher incidence of high blood pressure $(\mathrm{p}=0.006)$ and higher incidence of occupational exposure to solvents $(\mathrm{p}=0.047)$. Infants born of overweight or obese women had higher birth weight $(\mathrm{p}=0.02)$ and those born from obese women had lower Apgar scores at five minutes $(\mathrm{p}=0.02)$.

\section{Urinary analyses of pregnant women}


Obese mothers were distinguished by the first two latent variables, and overweight mothers to a slightly lesser extent. The ideal number of latent variables was one or two, depending on validation loop (mean $=1.77$ in the Normal vs. Overweight vs. Obese model). Separation of the 3 levels of BMI was significant according to the Q2 (mean=0.01, p=0.006) and R2 (mean=0.02, $\mathrm{p}=0.003$ ) criteria. The separation between normal-weight women and the rest of the population was significant according to the AUROC (mean=0.71, p=0.001), Q2 (mean=0.021, p=0.004) and R2 (mean $=0.05, \mathrm{p}=0.001$ ) criteria, as well as the separation between normal-weight and overweight women (AUROC=0.66, $\mathrm{p}=0.003 ; \mathrm{Q} 2=0.02, \mathrm{p}=0.001 ; \mathrm{R} 2=0, \mathrm{p}=0.008$ ). The separation between obese and the rest of the population was highly significant according to the AUROC (mean $=0.76, \mathrm{p}=0.001$ ) but not to the $\mathrm{Q} 2$ and $\mathrm{R} 2$. This can be explained by the small number of obese women in the population, leading to a lower performance of the classical parameters Q2 and R2 in PLS. The separation between obese and overweight women was not significant according to any criterion. The score plot derived from the PLS-DA modelling is shown in Figure 1. The parameters resulting from the validation procedures and permutation tests are described in Table 2.

Because hypertension and occupational exposure to solvent could also be associated with an increased risk in obesity, these characteristics were studied by PLS-DA modelling on urinary metabolic profile. The models did not produce any significant separation (data not shown).

Next, logistic and polytomous regressions were performed on metabolites having VIP above 2: direction of the associations and p-values using Kruskal-Wallis test were presented in Table 3. Hippurate and phenylalanine levels were lower in obese and overweight women, whereas urinary creatinine was higher. Lactate was higher in obese (though not in overweight) women, as were creatine, lysine, citrate and acetate. Two unknown signals $(\delta=6.925$ and $\delta=2.345 \mathrm{ppm})$ appeared modified between the BMI groups. 


\section{Serum analyses of cord-blood at birth}

The metabolic profiles of the cord-blood samples did not show any visual separation on the first latent variables, as shown in Figure 2. The parameters resulting from the validation procedure and permutation test are presented in Table 4. These validation procedures did not show any significant separation according to the BMI group, irrespective of the tested model. No bucket having a VIP above 2 was found significantly associated with BMI status by the Kruskal-Wallis test.

\section{Discussion}

Our work shows modification to seven urinary metabolites between obese, overweight, and normal-weight pregnant women, including hippurate, phenylalanine, lactate, creatine, lysine, citrate and acetate, without any measurable association with specific cord-blood metabolic profile at birth. The decrease in urinary hippurate and phenylalanine levels and the increase in creatinine levels were observed in both obese and overweight women. Increased urinary lactate, creatine, lysine, citrate and acetate levels concerned only the obese women. Hippurate, lactate and acetate are organic acids which had already been associated with obesity and type 2 diabetes, especially in studies investigating the influence of gut microbiota (Calvani et al., 2010; Dewulf et al., 2013; Phipps et al., 1998; Respondek et al., 2013; Salek et al., 2007; Waldram et al., 2009; Williams et al., 2002). In particular, the urinary excretion of hippurate has been associated with gut microbiota having a role in the metabolism of polyphenolic compounds (Lees et al., 2013). In addition, there is evidence to suggest that disruptions in gut flora and their relationship with the host are associated with the development of obesity (Gross, 2013). Decreases in urinary hippurate have been observed both experimentally and in humans (Calvani et al., 2010; Friedrich et al., 2012; Salek et al., 2007). 
An increase in lactate has already been shown in some studies - in urine, blood and hepatic tissue (Rull et al., 2009; Serkova et al., 2006). It has been shown that, like hippurate, lactate is linked to gut microflora, in particular to Propionibacterium (Dewulf et al., 2013; Respondek et al., 2013). Lactate is also a precursor of gluconeogenesis and an elevation could be a sign of hepatic disruptions in glucose and glycogen synthesis (Xie et al., 2012b).

Lastly, an increase in acetate levels has already been observed in the urine and blood of Zucker rat (Serkova et al., 2006; Waldram et al., 2009). Acetate is suspected to be linked with microbiome, and in particular with Bifidobacterium - which is already known to have a protective effect against obesity (Waldram et al., 2009).

It was also shown than amino-acid metabolism could be modified in the event of obesity (Lees et al., 2013). The increased urinary lysine we have observed in this study is consistent with experimental studies carried out in rats. Changes in lysine degradation were observed in obese Zucker rats compared to lean rats, and are potentially associated with impairment to energy metabolism, implying perturbations in insulin resistance (Salek et al., 2007). Nevertheless, other studies also showed a decrease in plasmatic lysine levels associated with an increase in insulin resistance in mice (Won et al., 2013) and a decrease in lysine levels in the adipose tissue of obese people (Hanzu et al., 2013). Moreover, lysine acetylation seems to play a role in some obesity-induced cancers (Lee et al., 2013). Finally, we know that protein nutrition can have a consequence on lipid metabolism (Gudbrandsen et al., 2008). Similar observations were made of phenylalanine; several authors have linked its increase with obesity (Kim et al., 2013; Wang et al., 2011; Whitehead et al., 2007). A relationship between obesity and the metabolism of branched-chain amino acids was hypothesized (Adams, 2011; Kim et al., 2013). On the other hand, Won et al. showed a decrease in urinary phenylalanine concentrations in obese mice (Won et al., 2013). Despite this discrepancy regarding modifications observed in lysine and 
phenylalanine levels, it could be concluded that obesity has an influence on amino acid metabolism, as has already been suggested in other works (Zhou et al., 2013).

Citrate is produced from fatty acids and glucose metabolism and is an intermediate in the citrate cycle for energy production. Its regulation involves insulin and glucose. The increased levels of citrate we observed are consistent with certain studies in diabetic or obese rats (Kim et al., 2009; Li et al., 2008; Shearer et al., 2008), suggesting a link with hyperglycaemia and insulin resistance, while lowered levels have sometimes been measured (Salek et al., 2007; Schirra et al., 2008; Zhao et al., 2010). The increased citrate levels could be associated with the increase in acetate and lactate levels, suggesting an up-regulation in the citrate cycle. In addition, changes in citrate levels could be associated with renal pathologies. It is possible that an increase in the urinary secretion of citrate may be a consequence of a metabolic stress induced by hyperglycaemia and/or dyslipidaemia, or a consequence of renal dysfunctions (Salek et al., 2007).

Creatinine is a break-down product of creatine metabolism in muscles. Urinary and blood increases in creatinine and creatine have been observed in obese rodents (Calvani et al., 2010; Duggan et al., 2011; Salek et al., 2007; Schirra et al., 2008; Williams et al., 2005; Zhao et al., 2010). This phenomenon could be explained by cardiac or skeletal muscle hypertrophy as an adaptation to support the increase of body mass induced by obesity (Xie et al., 2012b). Urinary secretion of creatinine is also used to measure renal function. An increase could be the consequence of renal dysfunctions, linked with obesity (Kim et al., 1969; Proczko et al., 2013). In recent years, studies have shown that NMR-based metabolomics on urine samples is able to identify obesity biomarkers. To the best of our knowledge, our study is the first to use metabolomics trying to investigate the mechanisms governing the transmission of obesity. Our inability to observe the effect of obese or overweight mothers on offspring metabolic profile must be put into perspective. First, the low number of obese women $(n=19)$ induces a low 
statistical power. Obesity measurement by BMI, calculated using physiological parameters (weight, height) collected by questionnaire may result in measurement errors, in particular an underestimation of obese women's weight, leading to a weak separation of BMI subgroups. Lastly, it is possible that certain modifications to metabolic profile are not visible at birth - but appear later.

The NMR technique used does have certain advantages: the analysis is highly quantitative, measures are reproducible and required preparation is minimal (Dumas et al., 2006; Smolinska et al., 2012). The other commonly-used technique in metabolomics is mass spectrometry coupled with chromatographic techniques, the advantage of which is the possibility of detecting metabolites in lower concentrations (Werner et al. 2008; Breitling et al. 2006). It would be interesting to reproduce this kind of study using mass spectrometry, in order to confirm and improve the results of our study.

\section{Concluding remarks}

Metabolomics has potential for the study of obesity and the identification of biomarkers, with the possibility of a global measurement of metabolic dysfunctions in a biological matrix. This study has shown several modifications to the urinary metabolic profile of obese and overweight pregnant women when compared with normal-weight pregnant women, yet without being able to show any modification to blood metabolic profile of offspring at birth. Changes observed include modifications to amino acid metabolism, citrate cycle, and microbiome-host relationships. More studies on large human samples will be necessary to establishing strong evidence on metabolic modifications involved in the transmission of obesity.

\section{Acknowledgments including grant information}


We acknowledge financial support from the EHESP School of Public Health, France. We gratefully acknowledge Marie Tremblay-Franco for helpful advice on statistics, and Sven Delaye for advice on English translation.

\section{References}

Adams, S.H., 2011. Emerging perspectives on essential amino acid metabolism in obesity and the insulin-resistant state. Adv. Nutr. Bethesda Md 2, 445-456. doi:10.3945/an.111.000737

Bonvallot, N., Tremblay-Franco, M., Chevrier, C., Canlet, C., Warembourg, C., Cravedi, J.-P., Cordier, S., 2013. Metabolomics tools for describing complex pesticide exposure in pregnant women in Brittany (France). PloS One 8, e64433. doi:10.1371/journal.pone.0064433

Bouanane, S., Merzouk, H., Benkalfat, N.B., Soulimane, N., Merzouk, S.A., Gresti, J., Tessier, C., Narce, M., 2010. Hepatic and very low-density lipoprotein fatty acids in obese offspring of overfed dams. Metabolism. 59, 1701-1709. doi:10.1016/j.metabol.2010.04.003

Bouchard, L., Hivert, M.-F., Guay, S.-P., St-Pierre, J., Perron, P., Brisson, D., 2012. Placental adiponectin gene DNA methylation levels are associated with mothers' blood glucose concentration. Diabetes 61, 1272-1280. doi:10.2337/db11-1160

Bouchard, L., Thibault, S., Guay, S.-P., Santure, M., Monpetit, A., St-Pierre, J., Perron, P., Brisson, D., 2010. Leptin gene epigenetic adaptation to impaired glucose metabolism during pregnancy. Diabetes Care 33, 2436-2441. doi:10.2337/dc10-1024

Breitling R., Pitt A.R., Barrett M.P. Precision Mapping of the Metabolome. Trends in Biotechnology. 2006;24(12):543-548.

Calvani, R., Miccheli, A., Capuani, G., Tomassini Miccheli, A., Puccetti, C., Delfini, M., Iaconelli, A., Nanni, G., Mingrone, G., 2010. Gut microbiome-derived metabolites characterize a peculiar obese urinary metabotype. Int. J. Obes. 2005 34, 1095-1098. doi:10.1038/ijo.2010.44 
Challier, J.C., Basu, S., Bintein, T., Minium, J., Hotmire, K., Catalano, P.M., Hauguel-de Mouzon, S., 2008. Obesity in pregnancy stimulates macrophage accumulation and inflammation in the placenta. Placenta 29, 274-281. doi:10.1016/j.placenta.2007.12.010

Chevrier, C., Limon, G., Monfort, C., Rouget, F., Garlantézec, R., Petit, C., Durand, G., Cordier, S., 2011. Urinary biomarkers of prenatal atrazine exposure and adverse birth outcomes in the PELAGIE birth cohort. Environ. Health Perspect. 119, 1034-1041. doi:10.1289/ehp.1002775

Dahlhoff, M., Pfister, S., Blutke, A., Rozman, J., Klingenspor, M., Deutsch, M.J., Rathkolb, B., Fink, B., Gimpfl, M., Hrabě de Angelis, M., Roscher, A.A., Wolf, E., Ensenauer, R., 2014. Peri-conceptional obesogenic exposure induces sex-specific programming of disease susceptibilities in adult mouse offspring. Biochim. Biophys. Acta 1842, 304-317. doi:10.1016/j.bbadis.2013.11.021

Dewulf, E.M., Cani, P.D., Claus, S.P., Fuentes, S., Puylaert, P.G.B., Neyrinck, A.M., Bindels, L.B., de Vos, W.M., Gibson, G.R., Thissen, J.-P., Delzenne, N.M., 2013. Insight into the prebiotic concept: lessons from an exploratory, double blind intervention study with inulintype fructans in obese women. Gut 62, 1112-1121. doi:10.1136/gutjnl-2012-303304

Dong, M., Zheng, Q., Ford, S.P., Nathanielsz, P.W., Ren, J., 2013. Maternal obesity, lipotoxicity and cardiovascular diseases in offspring. J. Mol. Cell. Cardiol. 55, 111-116. doi:10.1016/j.yjmcc.2012.08.023

Duggan, G.E., Hittel, D.S., Hughey, C.C., Weljie, A., Vogel, H.J., Shearer, J., 2011. Differentiating short- and long-term effects of diet in the obese mouse using (1) H-nuclear magnetic resonance metabolomics. Diabetes Obes. Metab. 13, 859-862. doi:10.1111/j.14631326.2011.01410.x

Dumas, M.-E., Maibaum, E.C., Teague, C., Ueshima, H., Zhou, B., Lindon, J.C., Nicholson, J.K., Stamler, J., Elliott, P., Chan, Q., Holmes, E., 2006. Assessment of analytical 
reproducibility of 1H NMR spectroscopy based metabonomics for large-scale epidemiological research: the INTERMAP Study. Anal. Chem. 78, 2199-2208. doi:10.1021/ac0517085

Farley, D.M., Choi, J., Dudley, D.J., Li, C., Jenkins, S.L., Myatt, L., Nathanielsz, P.W., 2010. Placental amino acid transport and placental leptin resistance in pregnancies complicated by maternal obesity. Placenta 31, 718-724. doi:10.1016/j.placenta.2010.06.006

Fiehn, O., 2002. Metabolomics--the link between genotypes and phenotypes. Plant Mol. Biol. 48, 155-171.

Friedrich, N., Budde, K., Wolf, T., Jungnickel, A., Grotevendt, A., Dressler, M., Völzke, H., Blüher, M., Nauck, M., Lohmann, T., Wallaschofksi, H., 2012. Short-term changes of the urine metabolome after bariatric surgery. Omics J. Integr. Biol. 16, 612-620. doi:10.1089/omi.2012.0066

Godfrey, K.M., Barker, D.J., 2000. Fetal nutrition and adult disease. Am. J. Clin. Nutr. 71, $1344 \mathrm{~S}-52 \mathrm{~S}$.

Gross, M., 2013. Does the gut microbiome hold clues to obesity and diabetes? Curr. Biol. CB 23, R359-362.

Gudbrandsen, O.A., Wergedahl, H., Liaset, B., Espe, M., Mørk, S., Berge, R.K., 2008. Dietary single cell protein reduces fatty liver in obese Zucker rats. Br. J. Nutr. 100, 776-785. doi:10.1017/S0007114508960906

Guzmán, C., Cabrera, R., Cárdenas, M., Larrea, F., Nathanielsz, P.W., Zambrano, E., 2006. Protein restriction during fetal and neonatal development in the rat alters reproductive function and accelerates reproductive ageing in female progeny. J. Physiol. 572, 97-108. doi:10.1113/jphysiol.2005.103903

Hanzu, F.A., Vinaixa, M., Papageorgiou, A., Párrizas, M., Correig, X., Delgado, S., Carmona, F., Samino, S., Vidal, J., Gomis, R., 2013. Obesity rather than regional fat depots 
marks the metabolomic pattern of adipose tissue: An untargeted metabolomic approach. Obes. Silver Spring Md. doi:10.1002/oby.20541

Inadera, H., 2013. Developmental origins of obesity and type 2 diabetes: molecular aspects and role of chemicals. Environ. Health Prev. Med. 18, 185-197. doi:10.1007/s12199-013-03288

Janesick, A., Blumberg, B., 2011. Endocrine disrupting chemicals and the developmental programming of adipogenesis and obesity. Birth Defects Res. Part C Embryo Today Rev. 93, 34-50. doi:10.1002/bdrc.20197

Jones, H.N., Woollett, L.A., Barbour, N., Prasad, P.D., Powell, T.L., Jansson, T., 2009. High-fat diet before and during pregnancy causes marked up-regulation of placental nutrient transport and fetal overgrowth in C57/BL6 mice. FASEB J. Off. Publ. Fed. Am. Soc. Exp. Biol. 23, 271-278. doi:10.1096/fj.08-116889

Karmaus, W., Osuch, J.R., Eneli, I., Mudd, L.M., Zhang, J., Mikucki, D., Haan, P., Davis, S., 2009. Maternal levels of dichlorodiphenyl-dichloroethylene (DDE) may increase weight and body mass index in adult female offspring. Occup. Environ. Med. 66, 143-149. doi:10.1136/oem.2008.041921

Kim, K.E., Onesti, G., Ramirez, O., Brest, A.N., Swartz, C., 1969. Creatinine clearance in renal disease. A reappraisal. Br. Med. J. 4, 11-14.

Kim, M.J., Yang, H.J., Kim, J.H., Ahn, C.-W., Lee, J.H., Kim, K.S., Kwon, D.Y., 2013. Obesity-related metabolomic analysis of human subjects in black soybean peptide intervention study by ultraperformance liquid chromatography and quadrupole-time-of-flight mass spectrometry. J. Obes. 2013, 874981. doi:10.1155/2013/874981

Kim, S.-H., Yang, S.-O., Kim, H.-S., Kim, Y., Park, T., Choi, H.-K., 2009. 1H-nuclear magnetic resonance spectroscopy-based metabolic assessment in a rat model of obesity induced by a high-fat diet. Anal. Bioanal. Chem. 395, 1117-1124. doi:10.1007/s00216-009-3054-8 
Kirk, S.L., Samuelsson, A.-M., Argenton, M., Dhonye, H., Kalamatianos, T., Poston, L., Taylor, P.D., Coen, C.W., 2009. Maternal obesity induced by diet in rats permanently influences central processes regulating food intake in offspring. PloS One 4, e5870. doi:10.1371/journal.pone.0005870

Lee, J.V., Shah, S.A., Wellen, K.E., 2013. Obesity, cancer, and acetyl-CoA metabolism. Drug Discov. Today Dis. Mech. 10, e55-e61. doi:10.1016/j.ddmec.2013.03.005

Lees, H.J., Swann, J.R., Wilson, I.D., Nicholson, J.K., Holmes, E., 2013. Hippurate: the natural history of a mammalian-microbial cometabolite. J. Proteome Res. 12, 1527-1546. doi:10.1021/pr300900b

Li, H., Xie, Z., Lin, J., Song, H., Wang, Q., Wang, K., Su, M., Qiu, Y., Zhao, T., Song, K., Wang, X., Zhou, M., Liu, P., Zhao, G., Zhang, Q., Jia, W., 2008. Transcriptomic and metabonomic profiling of obesity-prone and obesity-resistant rats under high fat diet. J. Proteome Res. 7, 4775-4783. doi:10.1021/pr800352k

Lowe, W.L., Karban, J., 2014. Genetics, genomics and metabolomics: new insights into maternal metabolism during pregnancy. Diabet. Med. J. Br. Diabet. Assoc. 31, 254-262. doi:10.1111/dme.12352

Magyar, D.M., Fridshal, D., Elsner, C.W., Glatz, T., Eliot, J., Klein, A.H., Lowe, K.C., Buster, J.E., Nathanielsz, P.W., 1980. Time-trend analysis of plasma cortisol concentrations in the fetal sheep in relation to parturition. Endocrinology 107, 155-159. doi:10.1210/endo-107$1-155$

Muhlhausler, B.S., Gugusheff, J.R., Ong, Z.Y., Vithayathil, M.A., 2013. Nutritional approaches to breaking the intergenerational cycle of obesity. Can. J. Physiol. Pharmacol. 91, 421-428. doi:10.1139/cjpp-2012-0353

Norman, J.D., Ferguson, M.M., Danzmann, R.G., 2014. Transcriptomics of salinity tolerance capacity in Arctic charr (Salvelinus alpinus): a comparison of gene expression profiles 
between divergent QTL genotypes. Physiol. Genomics 46, 123-137. doi:10.1152/physiolgenomics.00105.2013

Nuermaimaiti Tuersunjiang, J.F.O., 2013. Diet reduction in obese ewes from early gestation prevents glucose-insulin dysregulation and returns fetal adiposity and organ development to control levels. Am. J. Physiol. Endocrinol. Metab. doi:10.1152/ajpendo.00117.2013

O'Reilly, J.R., Reynolds, R.M., 2013. The risk of maternal obesity to the long-term health of the offspring. Clin. Endocrinol. (Oxf.) 78, 9-16. doi:10.1111/cen.12055

Orsi, C.M., Hale, D.E., Lynch, J.L., 2011. Pediatric obesity epidemiology. Curr. Opin. Endocrinol. Diabetes Obes. 18, 14-22. doi:10.1097/MED.0b013e3283423de1

Phipps, A.N., Stewart, J., Wright, B., Wilson, I.D., 1998. Effect of diet on the urinary excretion of hippuric acid and other dietary-derived aromatics in rat. A complex interaction between diet, gut microflora and substrate specificity. Xenobiotica Fate Foreign Compd. Biol. Syst. 28, 527-537. doi:10.1080/004982598239443

Proczko, M., Kaska, Ł., Kobiela, J., Stefaniak, T., Zadrożny, D., Śledziński, Z., 2013. Bariatric surgery in morbidly obese patients with chronic renal failure, prepared for kidney transplantation--case reports. Pol. Przegl. Chir. 85, 407-411. doi:10.2478/pjs-2013-0062

Respondek, F., Gerard, P., Bossis, M., Boschat, L., Bruneau, A., Rabot, S., Wagner, A., Martin, J.-C., 2013. Short-chain fructo-oligosaccharides modulate intestinal microbiota and metabolic parameters of humanized gnotobiotic diet induced obesity mice. PloS One 8, e71026. doi:10.1371/journal.pone.0071026

Rull, A., Vinaixa, M., Angel Rodríguez, M., Beltrán, R., Brezmes, J., Cañellas, N., Correig, X., Joven, J., 2009. Metabolic phenotyping of genetically modified mice: An NMR metabonomic approach. Biochimie 91, 1053-1057. doi:10.1016/j.biochi.2009.04.019

Salek, R.M., Maguire, M.L., Bentley, E., Rubtsov, D.V., Hough, T., Cheeseman, M., Nunez, D., Sweatman, B.C., Haselden, J.N., Cox, R.D., Connor, S.C., Griffin, J.L., 2007. A 
metabolomic comparison of urinary changes in type 2 diabetes in mouse, rat, and human. Physiol. Genomics 29, 99-108. doi:10.1152/physiolgenomics.00194.2006

Sarlio-Lähteenkorva, S., Silventoinen, K., Jousilahti, P., Hu, G., Tuomilehto, J., 2004. The association between thinness and socio-economic disadvantage, health indicators, and adverse health behaviour: a study of 28000 Finnish men and women. Int. J. Obes. Relat. Metab. Disord. J. Int. Assoc. Study Obes. 28, 568-573. doi:10.1038/sj.ijo.0802596

Schirra, H.J., Anderson, C.G., Wilson, W.J., Kerr, L., Craik, D.J., Waters, M.J., Lichanska, A.M., 2008. Altered metabolism of growth hormone receptor mutant mice: a combined NMR metabonomics and microarray study. PloS One 3, e2764. doi:10.1371/journal.pone.0002764

Serkova, N.J., Jackman, M., Brown, J.L., Liu, T., Hirose, R., Roberts, J.P., Maher, J.J., Niemann, C.U., 2006. Metabolic profiling of livers and blood from obese Zucker rats. J. Hepatol. 44, 956-962. doi:10.1016/j.jhep.2005.07.009

Shearer, J., Duggan, G., Weljie, A., Hittel, D.S., Wasserman, D.H., Vogel, H.J., 2008. Metabolomic profiling of dietary-induced insulin resistance in the high fat-fed C57BL/6J mouse. Diabetes Obes. Metab. 10, 950-958. doi:10.1111/j.1463-1326.2007.00837.x

Shelley, P., Martin-Gronert, M.S., Rowlerson, A., Poston, L., Heales, S.J.R., Hargreaves, I.P., McConnell, J.M., Ozanne, S.E., Fernandez-Twinn, D.S., 2009. Altered skeletal muscle insulin signaling and mitochondrial complex II-III linked activity in adult offspring of obese mice. Am. J.) Physiol. Regul. Integr. Comp. Physiol. 297, R675-681. doi:10.1152/ajpregu.00146.2009

Simmons, R.A., Suponitsky-Kroyter, I., Selak, M.A., 2005. Progressive accumulation of mitochondrial DNA mutations and decline in mitochondrial function lead to beta-cell failure. J. Biol. Chem. 280, 28785-28791. doi:10.1074/jbc.M505695200

Smink, A., Ribas-Fito, N., Garcia, R., Torrent, M., Mendez, M.A., Grimalt, J.O., Sunyer, J., 2008. Exposure to hexachlorobenzene during pregnancy increases the risk of overweight in 
children aged 6 years. Acta Paediatr. Oslo Nor. 1992 97, 1465-1469. doi:10.1111/j.16512227.2008.00937.x

Smit, S., van Breemen, M.J., Hoefsloot, H.C.J., Smilde, A.K., Aerts, J.M.F.G., de Koster, C.G., 2007. Assessing the statistical validity of proteomics based biomarkers. Anal. Chim. Acta 592, 210-217. doi:10.1016/j.aca.2007.04.043

Smolinska, A., Blanchet, L., Buydens, L.M.C., Wijmenga, S.S., 2012. NMR and pattern recognition methods in metabolomics: from data acquisition to biomarker discovery: a review. Anal. Chim. Acta 750, 82-97. doi:10.1016/j.aca.2012.05.049

Suter, M.A., Sangi-Haghpeykar, H., Showalter, L., Shope, C., Hu, M., Brown, K., Williams, S., Harris, R.A., Grove, K.L., Lane, R.H., Aagaard, K.M., 2012. Maternal high-fat diet modulates the fetal thyroid axis and thyroid gene expression in a nonhuman primate model. Mol. Endocrinol. Baltim. Md 26, 2071-2080. doi:10.1210/me.2012-1214

Symonds, M.E., Mendez, M.A., Meltzer, H.M., Koletzko, B., Godfrey, K., Forsyth, S., van der Beek, E.M., 2013. Early life nutritional programming of obesity: mother-child cohort studies. Ann. Nutr. Metab. 62, 137-145. doi:10.1159/000345598

Szymańska, E., Saccenti, E., Smilde, A.K., Westerhuis, J.A., 2012. Double-check: validation of diagnostic statistics for PLS-DA models in metabolomics studies. Metabolomics Off. J. Metabolomic Soc. 8, 3-16. doi:10.1007/s11306-011-0330-3

Vinayavekhin, N., Homan, E.A., Saghatelian, A., 2010. Exploring disease through metabolomics. ACS Chem. Biol. 5, 91-103. doi:10.1021/cb900271r

Waldram, A., Holmes, E., Wang, Y., Rantalainen, M., Wilson, I.D., Tuohy, K.M., McCartney, A.L., Gibson, G.R., Nicholson, J.K., 2009. Top-down systems biology modeling of host metabotype-microbiome associations in obese rodents. J. Proteome Res. 8, 2361-2375. doi:10.1021/pr8009885 
Wang, C., Feng, R., Sun, D., Li, Y., Bi, X., Sun, C., 2011. Metabolic profiling of urine in young obese men using ultra performance liquid chromatography and Q-TOF mass spectrometry (UPLC/Q-TOF MS). J. Chromatogr. B Analyt. Technol. Biomed. Life. Sci. 879, 2871-2876. doi:10.1016/j.jchromb.2011.08.014

Waterman, D.S., Bonner, F.W., Lindon, J.C. 2009. Review: Spectroscopic and statistical methods in metabonomics. Bioanalysis,1(9):1559-1578, doi:10.4155/bio.09.143

Wen, X., Triche, E.W., Hogan, J.W., Shenassa, E.D., Buka, S.L., 2011. Prenatal factors for childhood blood pressure mediated by intrauterine and/or childhood growth? Pediatrics 127 , e713-721. doi:10.1542/peds.2010-2000.

Werner E., Heilier J-F., Ducruix C., Ezan E., Junot C., Tabet J-C. Mass Spectrometry for the Identification of the Discriminating Signals from Metabolomics: Current Status and Future Trends. Journal of Chromatography B. 2008;871(2):143-163.

Whitehead, T.L., Holley, A.W., Korourian, S., Shaaf, S., Kieber-Emmons, T., Hakkak, R., 2007. (1)H nuclear magnetic resonance metabolomic analysis of mammary tumors from lean and obese Zucker rats exposed to 7,12-dimethylbenz[a]anthracene. Int. J. Mol. Med. 20, 573580.

WHO Expert Consultation, 2004. Appropriate body-mass index for Asian populations and its implications for policy and intervention strategies. Lancet 363, 157-163. doi:10.1016/S0140-6736(03)15268-3

Williams, R.E., Eyton-Jones, H.W., Farnworth, M.J., Gallagher, R., Provan, W.M., 2002. Effect of intestinal microflora on the urinary metabolic profile of rats: a (1)H-nuclear magnetic resonance spectroscopy study. Xenobiotica Fate Foreign Compd. Biol. Syst. 32, 783-794. doi:10.1080/00498250210143047

Williams, R.E., Lenz, E.M., Evans, J.A., Wilson, I.D., Granger, J.H., Plumb, R.S., Stumpf, C.L., 2005. A combined (1)H NMR and HPLC-MS-based metabonomic study of urine from 
obese (fa/fa) Zucker and normal Wistar-derived rats. J. Pharm. Biomed. Anal. 38, 465-471. doi:10.1016/j.jpba.2005.01.013

Won, E.-Y., Yoon, M.-K., Kim, S.-W., Jung, Y., Bae, H.-W., Lee, D., Park, S.G., Lee, C.H., Hwang, G.-S., Chi, S.-W., 2013. Gender-specific metabolomic profiling of obesity in leptindeficient ob/ob mice by $1 \mathrm{H}$ NMR spectroscopy. PloS One 8, e75998. doi:10.1371/journal.pone.0075998

Worley, B., Powers, R., 2013. Multivariate Analysis in Metabolomics. Curr. Metabolomics 1, 92-107. doi:10.2174/2213235X11301010092

Xie, B., Waters, M.J., Schirra, H.J., 2012a. Investigating potential mechanisms of obesity by metabolomics. J. Biomed. Biotechnol. 2012, 805683. doi:10.1155/2012/805683

Xie, B., Waters, M.J., Schirra, H.J., 2012b. Investigating potential mechanisms of obesity by metabolomics. J. Biomed. Biotechnol. 2012, 805683. doi:10.1155/2012/805683

Yan, X., Huang, Y., Zhao, J.-X., Rogers, C.J., Zhu, M.-J., Ford, S.P., Nathanielsz, P.W., Du, M., 2013. Maternal obesity downregulates microRNA let-7g expression, a possible mechanism for enhanced adipogenesis during ovine fetal skeletal muscle development. Int. J. Obes. 2005 37, 568-575. doi:10.1038/ijo.2012.69

Zambrano, E., Nathanielsz, P.W., 2013. Mechanisms by which maternal obesity programs offspring for obesity: evidence from animal studies. Nutr. Rev. 71 Suppl 1, S42-54. doi:10.1111/nure. 12068

Zhang, A., Sun, H., Wang, X., 2013. Power of metabolomics in biomarker discovery and mining mechanisms of obesity. Obes. Rev. Off. J. Int. Assoc. Study Obes. 14, 344-349. doi:10.1111/obr.12011

Zhao, L.-C., Zhang, X.-D., Liao, S.-X., Gao, H.-C., Wang, H.-Y., Lin, D.-H., 2010. A metabonomic comparison of urinary changes in Zucker and GK rats. J. Biomed. Biotechnol. 2010, 431894. doi:10.1155/2010/431894 
Zhou, Y., Qiu, L., Xiao, Q., Wang, Y., Meng, X., Xu, R., Wang, S., Na, R., 2013. Obesity and diabetes related plasma amino acid alterations. Clin. Biochem. 46, 1447-1452. doi:10.1016/j.clinbiochem.2013.05.045 


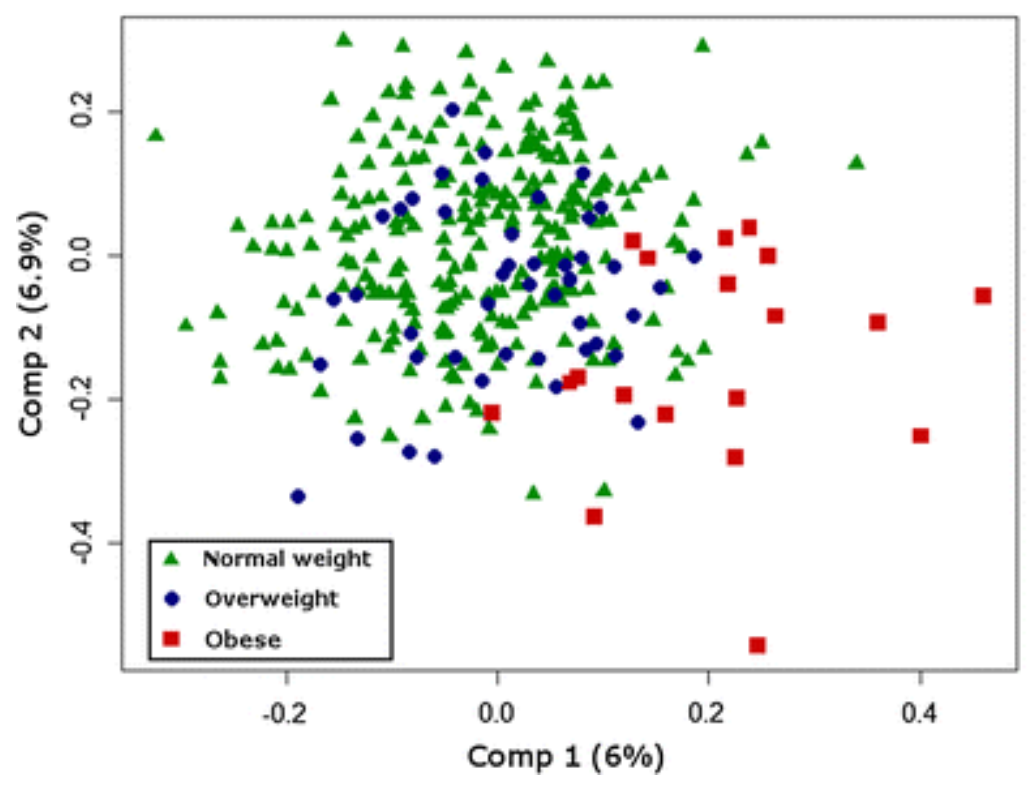

Figure 1: PLS-DA score plot from the 1H NMR urinary metabolic profile from 321 pregnant women. The score plot is the projection of observations onto the first two latent variables. The PLS-DA model was run on Pareto-scaled data $(\mathrm{N}=321, \mathrm{R} 2=0.02, \mathrm{Q} 2=0.01)$. Three groups of Body Mass Index (BMI). Green triangles: normal weight women, blue circles: overweight women; red squares: obese women. 


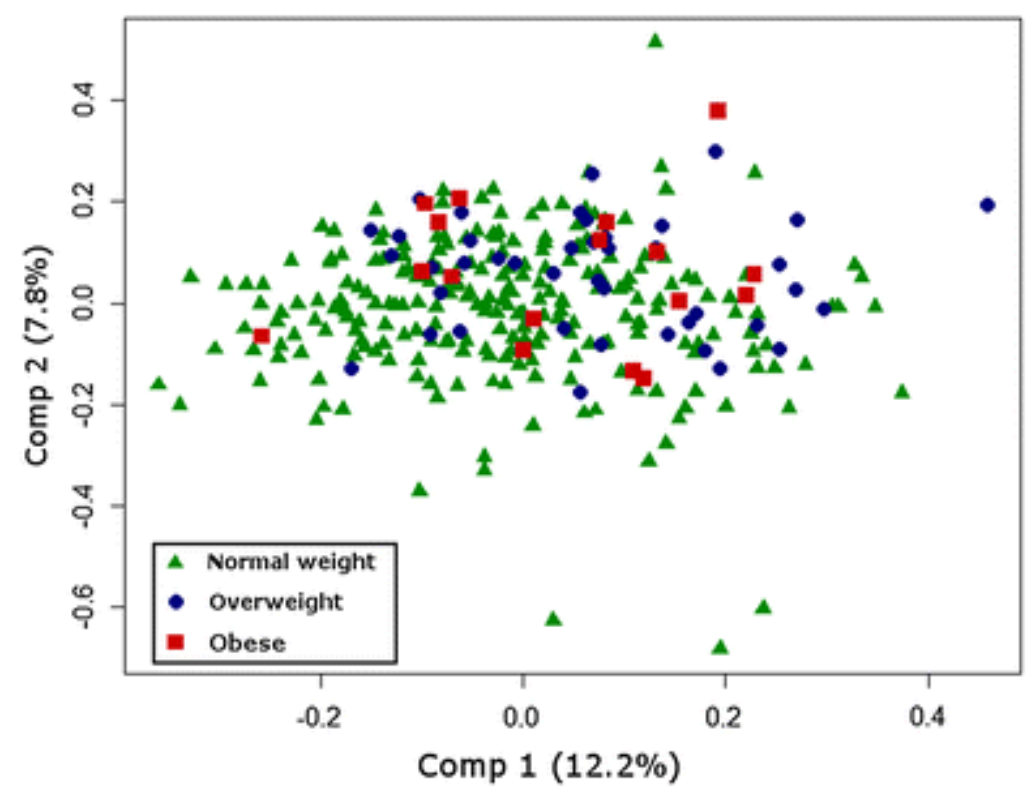

Figure 2: PLS-DA score plot from the 1H NMR cord-blood metabolic profile from 321 individuals. The score plot is the projection of observations onto the first two latent variables. The PLS-DA model was run on Pareto-scaled data, $(\mathrm{N}=324, \mathrm{R} 2=-0.04, \mathrm{Q} 2=-0.07)$. Three groups of Body Mass Index (BMI). Green triangles: normal weight women, blue circles: overweight women; red squares: obese women. 
Table 1: Characteristics of the 321 pregnant women enrolled in the metabolomics analysis according to their Body Mass Index (BMI). Three groups were identified according to the WHO definition: Normal-weight women $(18.5<\mathrm{BMI}<25)$, overweight women $(25<\mathrm{BMI}<30)$ and obese women $(\mathrm{BMI} \geq 30)$.

\begin{tabular}{|c|c|c|c|c|c|}
\hline Characteristics & $\begin{array}{c}\text { General } \\
\text { population } \\
(\mathbf{n}=\mathbf{3 2 1})\end{array}$ & $\begin{array}{l}\text { Normal-weight } \\
\text { women }(n=256)\end{array}$ & $\begin{array}{l}\text { Overweight } \\
\text { women } \\
(n=46)\end{array}$ & $\begin{array}{l}\text { Obese } \\
\text { women } \\
(n=19)\end{array}$ & p value ${ }^{1}$ \\
\hline \multicolumn{6}{|l|}{ Maternal characteristics } \\
\hline $\mathrm{BMI}($ mean $\pm \mathrm{SD})$ & $22.96+/-3.85$ & $21.36+/-1.64$ & $27.35+/-1.47$ & $33.89+/-2.96$ & \\
\hline $\begin{array}{l}\text { Maternal weight after } \\
\text { pregnancy, in } \mathrm{kg}(\text { mean } \pm \mathrm{SD})\end{array}$ & $74.67+/-11.16$ & $71.13+/-7.94$ & $83.13+/-5.95$ & $\begin{array}{c}100.67+/- \\
13.05\end{array}$ & \\
\hline Parity $=1(\mathrm{~N}, \%)$ & $134(41.88)$ & $116(45.49)$ & $13(28.26)$ & $5(26.32)$ & 0.03 \\
\hline Age $($ mean $\pm S D)$ & $30.27+/-4.22$ & $30.2+/-4.21$ & $30.77+/-4.55$ & $29.92+/-3.61$ & 0.78 \\
\hline Higher education $^{2}(\mathrm{~N}, \%)$ & $194(60.62)$ & $161(63.14)$ & $23(50)$ & $10(52.63)$ & 0.19 \\
\hline High blood pressure $(\mathrm{N}, \%)$ & $12(3.75)$ & $6(2.35)$ & $3(6.52)$ & $3(15.79)$ & 0.01 \\
\hline $\begin{array}{l}\text { Smoking in early pregnancy } \\
(\mathrm{N}, \%)\end{array}$ & $90(28.21)$ & $71(27.95)$ & $15(32.61)$ & $4(21.05)$ & 0.68 \\
\hline $\begin{array}{l}\text { Regular or occasional } \\
\text { alcohol consumption }(\mathrm{N}, \%)\end{array}$ & $51(15.94)$ & & $4(8.89)$ & $1(5.26)$ & 0.18 \\
\hline $\begin{array}{l}\text { Regular or occasional } \\
\text { occupational } \\
\text { exposure to solvents }(\mathrm{N}, \%)\end{array}$ & $138(50$ & $103(47.25)$ & $25(67.57)$ & $10(62.5)$ & 0.05 \\
\hline \multicolumn{6}{|l|}{ New-born characteristics } \\
\hline $\begin{array}{l}\text { Gestational age at birth in } \\
\text { weeks } \\
(\text { mean } \pm \mathrm{SD})\end{array}$ & $39.62+/-1.14$ & $39.59+/-1.15$ & $39.59+/-1.13$ & $40.11+/-1.05$ & 0.16 \\
\hline Male children $(\mathrm{N}, \%)$ & $157(48.91)$ & $125(48.83)$ & $23(50)$ & $9(47.37)$ & 1 \\
\hline Birth weight, in $\mathrm{g}($ mean $\pm \mathrm{SD})$ & $\begin{array}{l}3494.22+/- \\
393.13\end{array}$ & $3464.2+/-368.88$ & $\begin{array}{l}3598.48+/- \\
\quad 493.54\end{array}$ & $\begin{array}{l}3646.32+/- \\
\quad 382.03\end{array}$ & 0.06 \\
\hline Birth height, in $\mathrm{cm}$ (mean \pm SD) & $50.11+/-1.79$ & $50.06+/-1.73$ & $50.32+/-2.2$ & $50.21+/-1.36$ & 0.79 \\
\hline $\begin{array}{l}\text { Birth head circumference in } \mathrm{cm} \\
(\text { mean } \pm \mathrm{SD})\end{array}$ & $34.86+/-1.32$ & $34.82+/-1.31$ & $35.01+/-1.44$ & $35.03+/-1.12$ & 0.52 \\
\hline $\begin{array}{l}\text { Apgar score at } 5 \text { min }(\text { mean } \pm \\
\text { SD) }\end{array}$ & $9.9+/-0.43$ & $9.91+/-0.4$ & $9.93+/-0.25$ & $9.63+/-0.9$ & 0.21 \\
\hline
\end{tabular}

${ }^{1}$ Kruskal-Wallis test for continuous characteristics, chi-squared test for categorical characteristics.

${ }^{2}$ University degree 
Table 2: Validation of the PLS-DA regression models based on maternal urinary metabolic profiles in early pregnancy. Models were validated by a 3-2 double cross validation procedure. Inner loops were used to define the best number of Latent Variables (LV), using the lower PRESS criteria, while parameters were estimated in outer loops. P values were calculated using permutation tests (1000 iterations).

\begin{tabular}{|c|c|c|c|c|}
\hline Model & $\begin{array}{c}\text { Best number } \\
\text { of } L V \text { (mean } \\
+/- \text { SD) }\end{array}$ & Parameter & Mean +/- SD & p value \\
\hline \multirow[b]{2}{*}{ Normal vs. Overweight vs. Obese } & \multirow{2}{*}{$1.77+/-0.76$} & Q2 & $0.01+/-0.08$ & 0.006 \\
\hline & & $\mathrm{R} 2$ & $0.02+/-0.03$ & 0.003 \\
\hline \multirow{3}{*}{ Normal vs. others } & \multirow{3}{*}{$1.33+/-0.52$} & AUROC & $0.71+/-0.02$ & 0.001 \\
\hline & & Q2 & $0.02+/-0.12$ & 0.004 \\
\hline & & $\mathrm{R} 2$ & $0.05+/-0.04$ & 0.001 \\
\hline \multirow{3}{*}{ Obese vs. others } & \multirow{3}{*}{$1.77+/-0.83$} & AUROC & $0.76+/-0.05$ & 0.001 \\
\hline & & $\mathrm{Q} 2 \mathrm{Y}^{\prime}$ & $-0.11+/-0.11$ & 0.460 \\
\hline & & $\mathrm{R} 2$ & $-0.04+/-0.03$ & 0.070 \\
\hline \multirow{3}{*}{ Normal vs. Overweight } & \multirow{3}{*}{$1.03+/-0.05$} & AUROC & $0.66+/-0.03$ & 0.003 \\
\hline & & Q2 & $0.02+/-0.04$ & 0.001 \\
\hline & & $\mathrm{R} 2$ & $0+/-0.03$ & 0.008 \\
\hline \multirow{3}{*}{ Overweight vs. obese } & \multirow{3}{*}{$1.85+/-0.56$} & AUROC & $0.53+/-0.06$ & 0.370 \\
\hline & & Q2 & $-0.69+/-1.14$ & 0.540 \\
\hline & & $\mathrm{R} 2$ & $-0.19+/-0.13$ & 0.160 \\
\hline
\end{tabular}


Table 3: Metabolites linked with separation of the BMI groups in the urine of pregnant women, direction of the association and $\mathrm{p}$ value.

\begin{tabular}{|c|c|c|c|c|c|c|c|}
\hline & & & \multicolumn{2}{|c|}{ Obese } & \multicolumn{2}{|c|}{ Overweight } & \multirow[b]{2}{*}{$\begin{array}{c}\text { global } \\
\mathrm{p}\end{array}$} \\
\hline$\delta 1 \mathrm{H}(\mathrm{ppm})$ & $\begin{array}{l}\text { metabolite } \\
(\text { VIP }>2)\end{array}$ & BMI class & Trend & $\mathrm{p}$ & Trend & $\mathrm{p}$ & \\
\hline \multirow{3}{*}{$\begin{array}{l}7.56-7.53,7.97- \\
7.96,7.84-7.82, \\
7.64-7.62, \\
7.56-7.53\end{array}$} & \multirow{3}{*}{ Hippurate } & versus Normal & $\searrow$ & $<10-3$ & $\searrow$ & 0.002 & \multirow{3}{*}{$<10-3$} \\
\hline & & $\begin{array}{l}\text { Versus Normal + } \\
\text { Overweight }\end{array}$ & $\searrow$ & $<10-3$ & - & - & \\
\hline & & versus Overweight & $\searrow$ & 0.14 & nd & nd & \\
\hline \multirow{3}{*}{$\begin{array}{l}\text { 7.42-7.41, 7.36, } \\
3.99-3,98\end{array}$} & \multirow{3}{*}{ Phenylalanine } & versus Normal & $\searrow$ & $<10-3$ & $\searrow$ & 0.04 & \multirow{3}{*}{$<10-3$} \\
\hline & & $\begin{array}{l}\text { versus Normal + } \\
\text { Overweight }\end{array}$ & $\searrow$ & $<10-3$ & nd & nd & \\
\hline & & versus Overweight & $\searrow$ & 0.006 & nd & nd & \\
\hline \multirow{3}{*}{$4.12,1.34-1.32$} & \multirow{3}{*}{ Lactate } & versus Normal & $\nearrow$ & $<10-3$ & $\nearrow$ & 0.21 & \multirow{3}{*}{$<10-3$} \\
\hline & & $\begin{array}{l}\text { versus Normal + } \\
\text { Overweight }\end{array}$ & $\nearrow$ & $<10-3$ & nd & nd & \\
\hline & & versus Overweight & $\lambda$ & 0.003 & nd & nd & \\
\hline \multirow{3}{*}{$4.06,3.05$} & \multirow{3}{*}{ Creatinine } & versus Normal & $\nearrow$ & 0.02 & $\nearrow$ & 0.002 & \multirow{3}{*}{$<10-3$} \\
\hline & & $\begin{array}{l}\text { versus Normal + } \\
\text { Overweight }\end{array}$ & $\lambda$ & 0.05 & nd & nd & \\
\hline & & versus Overweight & $=$ & 0.88 & nd & nd & \\
\hline \multirow{3}{*}{$3.955,3.045$} & \multirow{3}{*}{ Creatine } & versus Normal & $\nearrow$ & 0.03 & $=$ & 0.74 & \multirow{3}{*}{0.15} \\
\hline & & $\begin{array}{l}\text { versus Normal + } \\
\text { Overweight }\end{array}$ & $\nearrow$ & 0.04 & nd & nd & \\
\hline & & versus Overweight & $\nearrow$ & 0.52 & nd & nd & \\
\hline \multirow{3}{*}{3.015} & \multirow{3}{*}{ Lysine } & versus Normal & $\nearrow$ & 0.005 & $=$ & 0.96 & \multirow{3}{*}{0.06} \\
\hline & & $\begin{array}{l}\text { versus Normal + } \\
\text { Overweight }\end{array}$ & $\nearrow$ & 0.004 & nd & nd & \\
\hline & & versus Overweight & $\nearrow$ & 0.009 & nd & nd & \\
\hline \multirow{3}{*}{$\begin{array}{l}2.69,2.67,2.65- \\
2.64,2.56-2.52\end{array}$} & \multirow{3}{*}{ Citrate } & versus Normal & $\nearrow$ & $<10-3$ & $=$ & 0.84 & \multirow{3}{*}{0.01} \\
\hline & & $\begin{array}{l}\text { versus Normal + } \\
\text { Overweight }\end{array}$ & $\nearrow$ & $<10-3$ & nd & nd & \\
\hline & & versus Overweight & $\nearrow$ & 0.01 & nd & nd & \\
\hline \multirow{3}{*}{1.925} & \multirow{3}{*}{ Acetate } & versus Normal & $\nearrow$ & 0.06 & $\nearrow$ & 0.17 & \multirow{3}{*}{0.03} \\
\hline & & $\begin{array}{l}\text { versus Normal + } \\
\text { Overweight }\end{array}$ & $\nearrow$ & 0.09 & nd & nd & \\
\hline & & versus Overweight & $=$ & 0.43 & nd & nd & \\
\hline
\end{tabular}

$\mathrm{p}$ value are the result of a likelihood ratio test in logistic regression modelling or in ordered polytomous regression Normal < Overweight < Obesity (global $\mathrm{p}$ value). To ensure the normality of continuous variables, logarithms of hippurate, phenylalanine, lactate, creatinine and creatine were used. Acetate has been used as a categorical variable, with a cut-off at the median. VIP: Variable Importance in the Projection. nd: non determined 
Table 4: Validation of the PLS-DA regression models based on cord-blood metabolic profiles at birth. Models were validated by a 3-2 double cross validation procedure. Inner loops used to define the best number of Latent Variables (LV), using the lower PRESS criteria, while the parameters were estimated in the outer loops. P values were calculated using permutation test (1000 iterations).

\begin{tabular}{|c|c|c|c|c|}
\hline Model & $\begin{array}{l}\text { Best number of } \\
\text { LV (mean +/- } \\
\text { SD) }\end{array}$ & Parameter & Mean +/- SD & p value \\
\hline \multirow{2}{*}{ Normal vs. Overweight vs Obese } & \multirow{2}{*}{$1.6+/-1.37$} & Q2 & $-0.07+/-0.06$ & 0.594 \\
\hline & & $\mathrm{R} 2$ & $-0.04+/-0.03$ & 0.474 \\
\hline \multirow{3}{*}{ Normal vs. others } & \multirow{3}{*}{$1.13+/-0.23$} & AUROC & $0.53+/-0.05$ & 0.339 \\
\hline & & Q2 & $-0.06+/-0.03$ & 0.513 \\
\hline & & R2 & $-0.04+/-0.03$ & 0.314 \\
\hline \multirow{3}{*}{ Obese vs. others } & \multirow{3}{*}{$1.08+/-0.14$} & AUROC & $0.45+/-0.04$ & 0.711 \\
\hline & & Q2 & $-0.06+/-0.02$ & 0.530 \\
\hline & & $\mathrm{R} 2$ & $-0.06+/-0.02$ & 0.530 \\
\hline \multirow{3}{*}{ Normal vs. Overweight } & \multirow{3}{*}{$1.55+/-0.77$} & AUROC & $0.53+/-0.04$ & 0.322 \\
\hline & & Q2 & $-0.12+/-0.05$ & 0.845 \\
\hline & & $\mathrm{R} 2$ & $-0.08+/-0.03$ & 0.653 \\
\hline \multirow{3}{*}{ Overweight vs. Obese } & \multirow{3}{*}{$1.37+/-0.48$} & AUROC & $0.39+/-0.06$ & 0.830 \\
\hline & & Q2 & $-0.45+/-0.14$ & 0.720 \\
\hline & & $\mathrm{R} 2$ & $-0.37+/-0.08$ & 0.640 \\
\hline
\end{tabular}

